\title{
Sciendo
}

Transport and Telecommunication, 2022, volume 23, no. 1, 93-101

Transport and Telecommunication Institute, Lomonosova 1, Riga, LV-1019, Latvia

DOI 10.2478/ttj-2022-0009

\section{OCCUPANCY ESTIMATION AT BUS STOPS THROUGH WI-FI CONNECTIVITY ASSESSMENT - A STUDY IN GUAYAQUIL CITY}

\author{
Viviana Mero Cheme ${ }^{1}$, Martin Herrera Martinez, \\ Rayner Durango ${ }^{3}$, V. Sanchez Padilla ${ }^{4}$ \\ ESPOL Polytechnic University, Escuela Superior Politécnica del Litoral, \\ Telematics Engineering Program, P.O. Box 09-01-5863, Guayaquil-Ecuador \\ 'vmero@espol.edu.ec, ${ }^{2}$ maemherr@espol.edu.ec, ${ }^{3}$ rdurango@espol.edu.ec, ${ }^{4}$ vladsanc@espol.edu.ec
}

\begin{abstract}
Guayaquil is one of the most congested cities on the American continent. Several users cannot access on-time transport service according to the demand requested at bus stops. This work presents a simulation of the Wi-Fi technology to determine the number of users present at a bus stop. The objective is to know an estimation of them in different time intervals throughout the day, which could be useful for several actions, e.g., to set up a better distribution of transportation schedules or to place the bus stops in more demanding sites by users. The methodology included simulation scenarios for user counting at the bus stops. The results depicted that Wi-Fi technology performed suitable even in high-level attenuation scenarios.
\end{abstract}

Keywords: Bus stops, design thinking, transport system, user counting, Wi-Fi assessment, Wi-Fi simulation

\section{Introduction}

Guayaquil is the second most populated city in Ecuador, located in the South Pacific of the American continent, with approximately 2.3 million inhabitants (INEC, 2017). About $70 \%$ of the citizens travel to different destinations for different activities. The destinations are mostly to the midtown, being the most traffic area. On the other hand, the urban transport system has approximately fifty routes that cover six large sectors, with approximately 2,700 distributed buses, which maximize the frequency of the units in the places of greatest demand. According to the city's municipal transit agency, near 500,000 vehicles circulate in the city, of which $39 \%$ are automobiles, $26 \%$ motorcycles, and $35 \%$ other types (El Universo, 2019). The challenge of the city is to transport thousands of people daily, but optimizing resources. According to the congestion and mobility study carried out by (INRIX, 2020), the hours lost during congestion and intensive traffic generated by several means of transport, positions Guayaquil in the top 25 of the most congested cities in Latin America and the world. The study shows as result an average travel speed of approximately $20 \mathrm{~km} / \mathrm{h}$, which can determine a 50 to $100 \%$ difference in the travel time used between a vehicle and urban transport means.

Guayaquil's urban transportation system differentiates two subsystems that operate simultaneously, such as the Municipal Urban Mass Transportation (Metrovía System) and the integrated urban transportation system (SITU, Spanish acronym). Based on interviews, we realized the managers of the bus transport cooperatives do not have control of the information of how many users are located at bus stops, turning into a problem of disorganization concerning the quantity and frequencies of transport units, which they do not analyze. The consequences of this lack of organization could lead to an inefficient operation of the transport system, either not optimizing resources or reducing the discomfort of users. Although the Municipality has implemented improvements, some sectors allege that the current transport system does not meet user demand (El Universo, 2019). The urban bus transport system is fundamental for the proper functioning of a city, which is why the service must operate as efficiently as possible. Besides, it is a system of public interest because the operations involved for the citizens and city. Knowing the number of people who are at a bus stop is an important variable that directly affects the performance of the urban transport system and its participants, influencing schedules, user waiting time, travel time, among others.

Several types of research aim at improving urban transport systems based on different variables, models, and applications based on engineering (Sanchez Padilla et al., 2020), (Siuhi et al., 2021), (Makki 
et al., 2020), (Lopez \& Lozano, 2016). The objective of this proposal is to present a user monitoring analysis based on open source tools, including programming in MATLAB, to determine the density of people located at an urban bus stop by the assessment of Wi-Fi as wireless technology configured on users' mobile devices.

\section{Bus transportation systems}

The Metrovía System bases its operations on a BRT (Bus Rapid Transit) model. It consists of articulated and feeder buses with exclusive lanes to transit and transport passengers. The stations consist of different stops located approximately 300 meters apart. The implementation of the stations or bus stops took into account the people's density in the area, the number of concurrent passengers, and the number of articulated buses assigned to the bus stop. Figure 1 shows the models, classified in a) booth type stations, b) pedestrian crossing type stations, and c) integration stations (Naranjo \& Arellano, 2017).

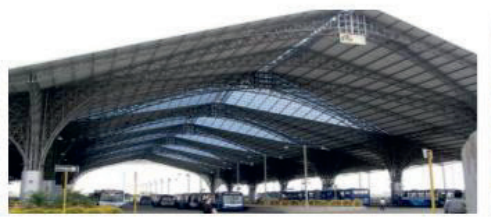

(a)

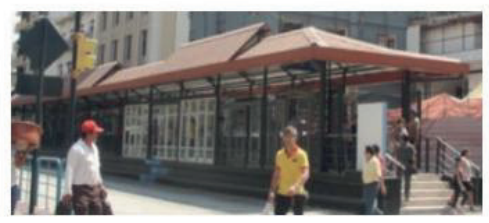

(b)

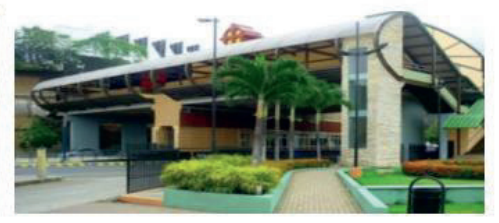

(c)

Figure 1. Types of bus stations in the Metrovía System

On the other hand, in recent years the SITU system has included a reorganization and control of city traffic making use of technologies (Municipality of Guayaquil, 2018). The main change was the progressive deployment of fifteen road corridors, smart stops, and both vertical and horizontal signage. In addition, the buses have GPS to control the travel times, arrival at the different stops, and departure time, having enabled Wi-Fi in many of the buses, as well as a panic button for emergency cases (ATM, 2017). The system integrates a mobile application for Android and iOS devices to gather information about bus travel times, the commuting between stops or incidents. The application obtains information from users through GPS devices when the user is using mobile data (ATM, 2018). Figure 2 depicts a photo of a SITU bus stop.

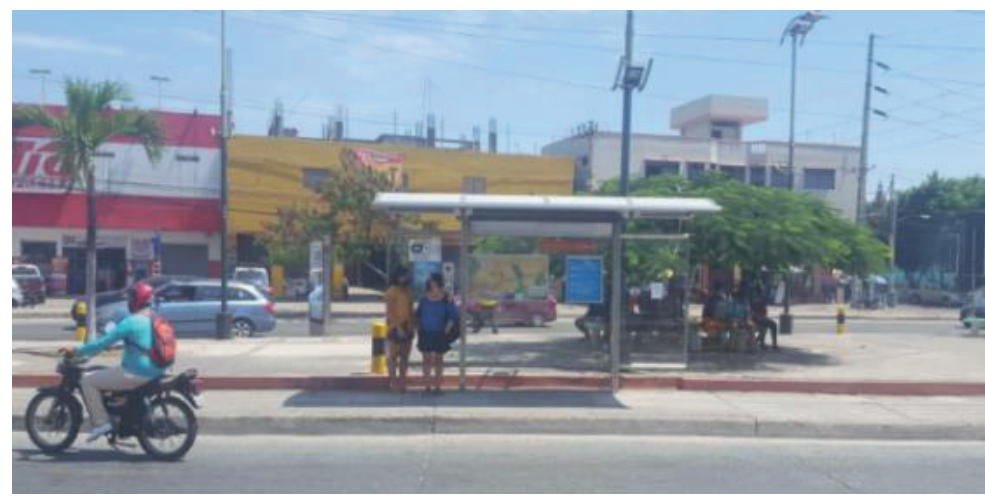

Figure 2. Bus stop of the SITU System

\section{Related work}

The measurement of people in a defined area has become a topic of interest, as shown in (Mehmood et al., 2019), (Zhang et al., 2014), (Barth \& Galante, 2016), and (Li et al., 2020). Varieties of measurements methods have used different technologies. For instance, the authors in (Li et al., 2015) propose a counting system based on smartphones before the traditional ones based on sensors using fixed sensing points. The system collects significant Wi-Fi signals to count people using a device that improves signal quality using the Wiener filter and Newton interpolation. A neural layer relates Wi-Fi signals and the number of people, analyzing received Wi-Fi signals, using the RSS linear approximation methodology, sequential people counting, and the device itself, which is the Wi-Counter. The sequential 
counting depends on temporal changes, with values experienced fluctuations. However, the device considered less abrupt changes and stable performance, similar to the linear approximation method used. While the authors in (Khodabandelou et al., 2016) focus on the metadata of mobile network traffic to calculate the population density on an urban scale. This estimates the fixed and dynamic population of a certain area by adapting different scenarios in an urban area. It detects the users when they connect to the mobile network, e.g., for calling, text messaging or Internet browsing. It does not detect users if they do not use any of these services.

The authors in (Wang et al., 2014) present a similar work to the present proposal, in which they use Wi-Fi signals to monitor the queues at places of massive affluence. They deem a minimal infrastructure to use a single monitor placed near the service area together with the transmission of telephones. The sensor near the beginning of the queues is responsible for measuring the signal strength emitted by the smartphones. They chose Wi-Fi as the wireless technology to evaluate because of the coverage range it provides and the ease for monitoring. The two methods tested by them were the recognition of critical time points and the Bayesian network model, which applies to a wide variety of queues in different scenarios.

Finally, a study carried out by (Georgievska et al., 2019) determines the prevention and warning of overcrowded events. They focus on anonymous, non-participant, and indoor estimation regarding the location of smartphones. The model used is probabilistic with the analysis of large data amounts, aiming at three objectives, such as the ambiguity of indoor Wi-Fi, the randomness of MAC addresses when the device is not connected, and the received packets volatility. They attained accurate measurements as the number of people increased.

\section{Methodology}

\subsection{Background}

There are more than 6,000 access points for data connectivity implemented by the Municipality of Guayaquil, in which citizens use them to connect their mobile devices to the Internet (El Universo, 2020). Additionally, due to the promotion of gadgets, users connect wearable devices through short-range wireless technologies, such as Bluetooth. This study focuses on Wi-Fi for the occupancy assessment of people located at a bus stop, using the design thinking technique (Quilambaqui Jara et al., 2019) to establish the friction points of users using the transport system. The three techniques used to empathize and get information of feelings and opinions of the users about the transport system were the map of actors, the Ishikawa diagram, and surveys of citizens without segmentation or discrimination.

The map of actors allowed us to know the parts that conform and relate (directly and indirectly) to the Guayaquil transportation system, addressing interests, importance, and beneficiaries. Figure 3 shows three groups closely related to the urban transport. Meanwhile, the Ishikawa diagram (Cahyana, 2018) allowed us to identify the causes and effects of the problem, as well as the discomfort felt by users who frequently use the urban transport system. Figure 4 depicts the relationship between the experiences of the users of the transport system and the possible causes of dissatisfaction with the current system.

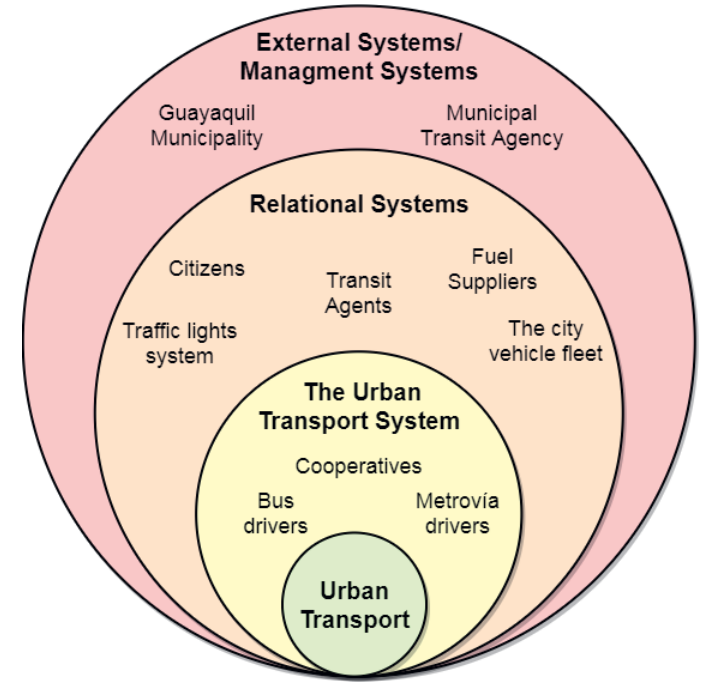

Figure 3. Map of actors of the urban transport system in Guayaquil 


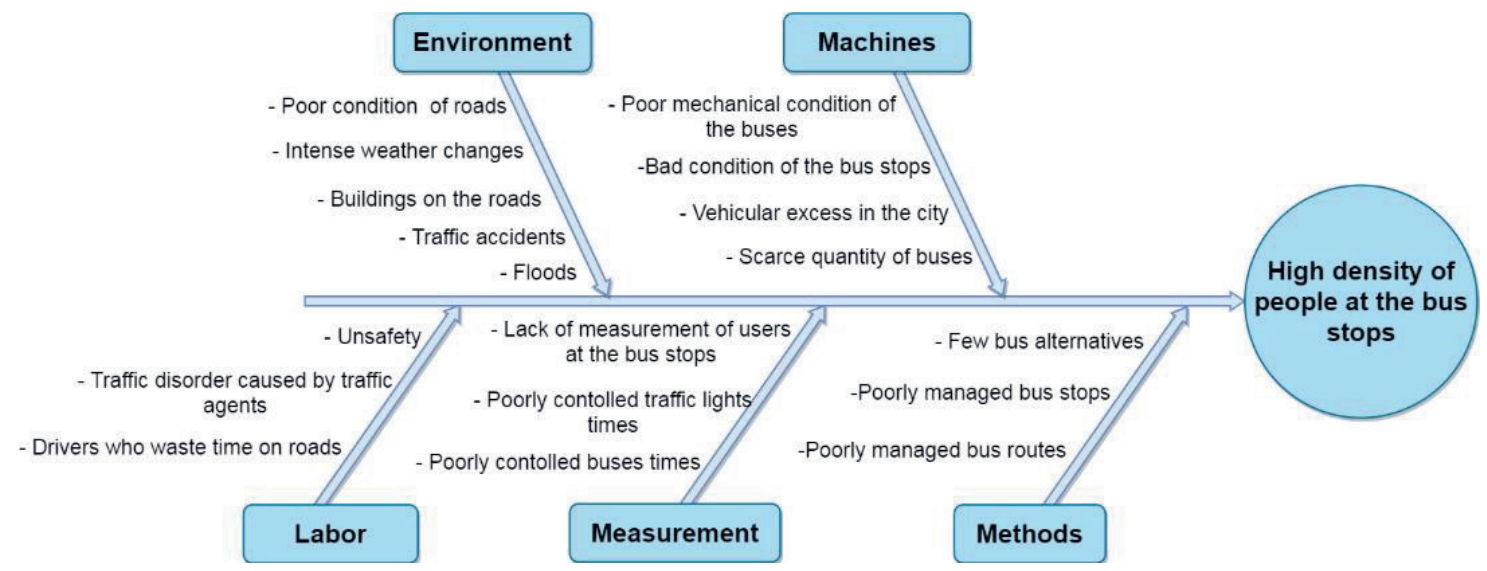

Figure 4. Cause and effect diagram

Finally, a survey let us know the aspects related to the number of buses that the users take to reach to their destination, travel times, and problems that the current transport system presents from the user's perception. At the same time, it allows identifying the network connection technology with which the users are familiar when they are not at home. Equation (1) provides a validation of the sample with the respective error and confidence value (Valdivieso et al., 2011). In (1), $\mathrm{N}$ is the size of the population of the city of Guayaquil; $e$ is the margin of error that considers how similar the response of those surveyed will be to the general opinion, where the lower the margin of error, the more accurate the answer will be. The variable $Z$ reflects the chosen level of confidence, representing the standard deviation that a value can suffer causing it to move away from the mean; $\mathrm{p}$ represents the proportion of individuals, whose ideal value is 0.5 because the user may or may not use the buses. Additionally, the confidence level indicates the confidence in the answers of the respondents.

Sample size $=\frac{\frac{z^{2} \times p(1-p)}{e^{2}}}{1+\frac{z^{2} \times p(1-p)}{e^{2} N}}$.

Due to the worldwide health emergency, a suitable sample number was expected for the survey. With the following values, we achieved the goal: N, 2.3 million; e, 9\%; confidence level, 95\%; Z, 1.96; p, 0.5. To have a statistically valid sample, we needed approximately 119 people to survey. However, we obtained 128 responses. The survey sought to know the percentage of active users of the urban transport system, the frequency of use, number of articulated vehicles they use to reach a destination, what they believe are the main problems, and what type of wireless network they use. We computed the following information from them:

- From 128 respondents, 124 use the urban transport system (90.5\% of the total).

- From 122 responses, 52 people use urban transport 2 to 4 days a week.

- From 122 responses: 41 people took 40 minutes to 1 hour, 33 people took 30 minutes to 40 minutes, 32 people took 20 minutes to 30 minutes and 16 people took more than 1 hour to reach their destinations.

- 60 respondents take two buses and 52 use only one bus. Only 9 respondents use three buses or more.

- "Few units to cover demand" is the main problem of the urban transport system according to 61 respondents. "Too much waiting time per unit" according to 53 respondents. "Excess of vehicles" according to 40 respondents, and "Not well-managed bus routes" according to 34 .

- From 126 responses, 111 respondents use mobile networks to connect to the Internet and 15 respondents use the Municipal Wi-Fi network.

\subsection{Simulation tools}

We used different tools for the simulation, such as GNS3, VirtualBox, CORE, and MATLAB. For instance, GNS3 is an open-source and freely distributed software, which is a graphic simulator used in 
student-level and corporate-level research to improve technological infrastructure. This software emulates, configures, tests, and solves problems in either virtual or real networks. It works in conjunction with virtual machine simulators, such as VMware or VirtualBox (Korniyenko et al., 2019). Meanwhile, we deemed VirtualBox because it allows us to simulate, manage and configure multiple virtual machines. In addition, it allows the managing of network components, such as virtual environments. It is available for Microsoft Windows, Linux, and Mac platforms (Vojnak et al., 2019).

In addition, we considered the Common Open Research Emulator (CORE), since it can simulate a data network through a graphical interface through different network topologies. It has a WLAN tool to create different nodes, where each node represents a lightweight virtual machine, applicable to use it with Linux and FreeSDB environments (Ahrenholz et al., 2011). Finally, we used MATLAB because it is executable in several environments, including open-source or proprietary applications. It approaches data calculation and plotting, script execution, and modeling, being compatible with multipurpose languages. Its advantages focus on its versatility in simple syntax engineering applications (Okereke \& Keates, 2018).

\subsection{Scenario for simulation}

Figure 5 shows the proposed scenario. User A and User B are users who approach the bus stops to wait for a bus. Depending on the security conditions or need, users connect to the Wi-Fi available and closer, where Wi-Fi connections detect the connectivity of the user. Once the count of a connected user has finished, it will then be able to continue detecting any enabled connections. The presence of an Internet access point is crucial for the success of the measurement, especially if this is located at a distance without obstacles in order to detect the users through their Wi-Fi devices at a bus stop.

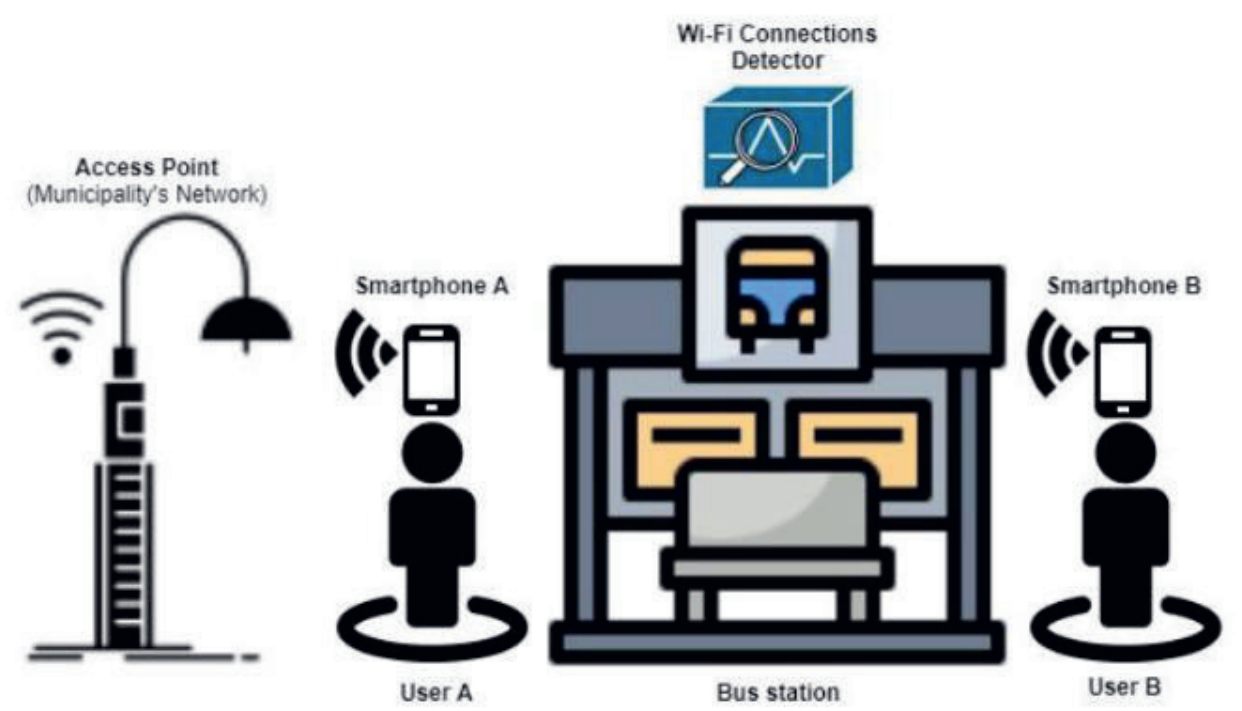

Figure 5. Wi-Fi-based simulated scenario

For the simulation, we used coding based on MATLAB for counting. We defined the variables of random users arriving at the bus stop, such as their location in $x$ and $y$ coordinates, their arrival time following an exponential distribution, the location and coverage area of the Internet access point, means of access, transmission, and noise. The code consists of four functions, where the main one was the Wi-Fi function, followed by Path Loss PL, Capacity File TX, and Capacity Update.

\subsection{Limitations}

One of the main challenges of this project is that the user must be connected to the access point installed near the bus stops to make the detection. The scope of the access point will depend on its power and location. Based on the aforementioned, a potential limitation is that people do not connect or freely use their mobile devices due to insecurity in the surroundings. Another limitation is that not everyone has mobile devices that can be discoverable. Finally, simulation tools must be up-to-date, preferably with support for the programming language used for avoiding conflicts with software libraries. 


\section{Results analysis}

We carried out the simulation with fifty people detected. We randomly generated the users according to the models for estimating the arrival times of them at the bus stops, noting that they enter and leave the system at random times. The scenario is similar to that of a bus stop during rush hour (18:00). Figure 6 depicts the distribution of users along a reference area for the stop, while Figure 7 shows the distance of each user to the access point. The users were located assigning them specific coordinates on the $\mathrm{Y}$-axis and the $\mathrm{X}$-axis, as well as the access point was located with its respective preset position coordinates.

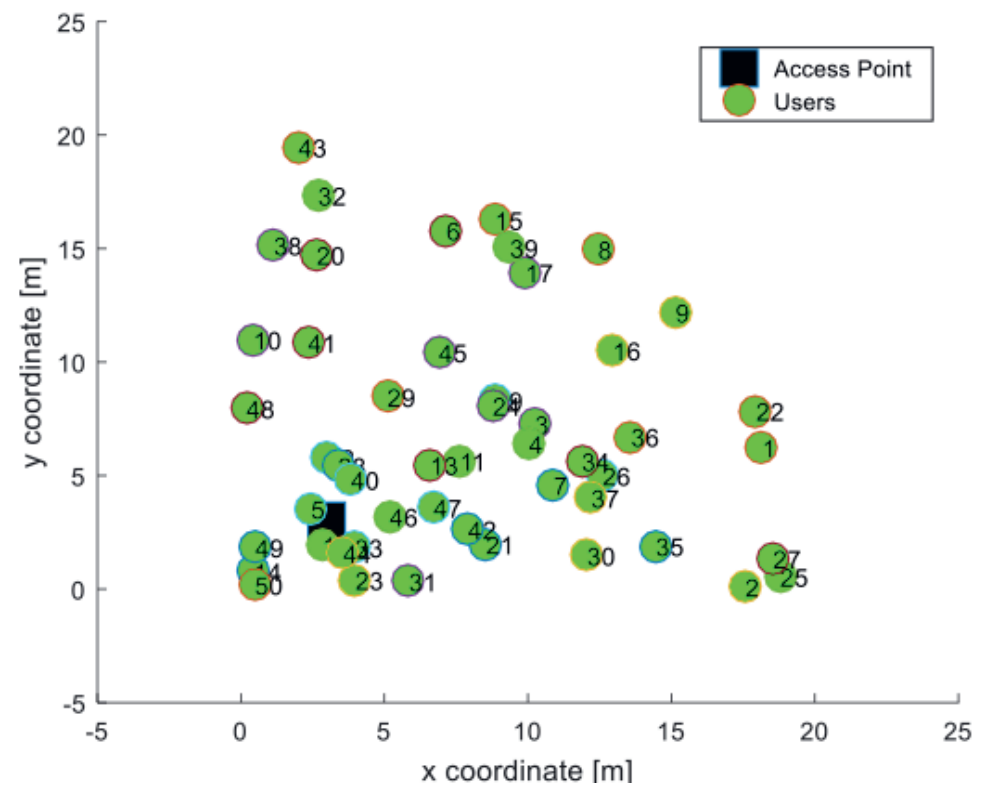

Figure 6. Location reference of the users respect an access point

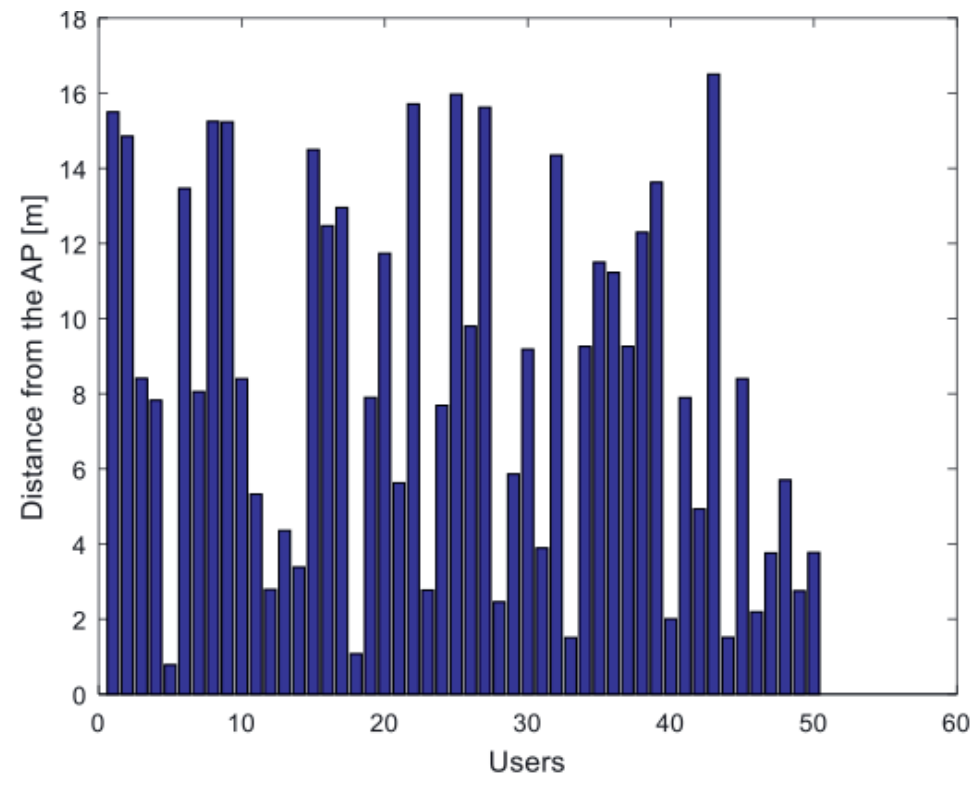

Figure 7. Distance from each user to the access point

A reference distance of one meter was defined where the attenuation behaves as free space attenuation. For distances greater than one meter, we applied the model for urban areas, which registered an attenuation of approximately $-12 \mathrm{dBm}$ each time the distance multiplied by two. Figure 8 shows the attenuation of the signal considering the distances of each user concerning the access point based on the general linear attenuation model specific for urban areas. 


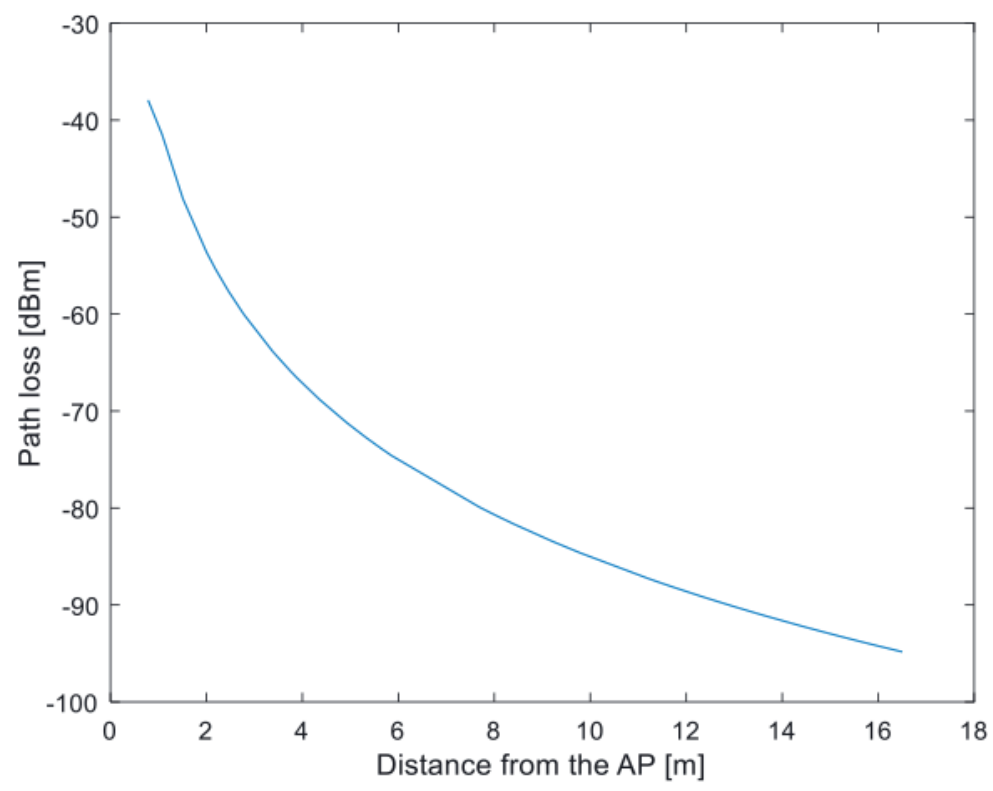

Figure 8. Path loss related to the distance of each user to the access point

Considering the access point power of $20 \mathrm{dBm}$ and an operation frequency of $2.4 \mathrm{GHz}$, it relates the quality of the signal in the system, including the attenuations, as well as the intensity of the signal received per user. The signal strength for the selected simulation ranges from $-30 \mathrm{dBm}$ (excellent) to -75 $\mathrm{dBm}$ (not recommended). On the other hand, the minimum signal for a reliable connectivity is $-80 \mathrm{dBm}$. According to this analysis, it was possible to determine the critical coverage distance for the simulation under the established attenuation conditions, being 21.28 meters from the access point. This value approximates how far a bus stop user can be detected, not guaranteeing its permanence at the location after a large period. Figure 9 shows the received power based on critical distance.

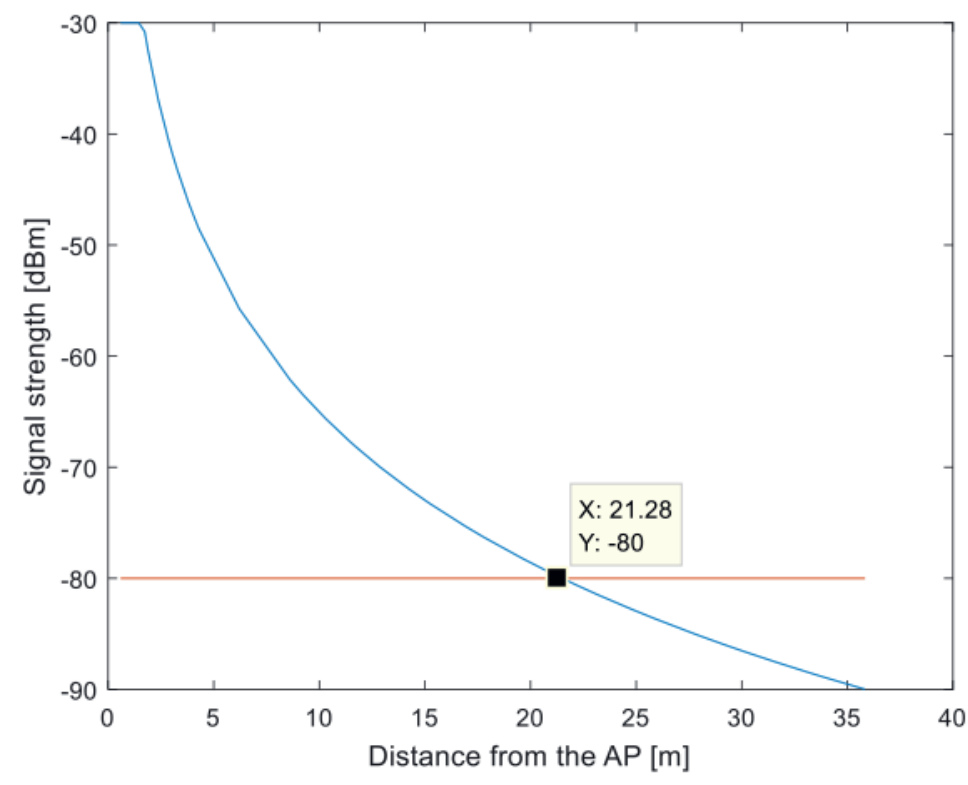

Figure 9. Received power intensity versus critical distance of the users

\section{Conclusions}

During the simulation process, we did not considered people who walked or exercised around the bus stop, addressing they were not going to wait for a bus. Similarly, the coverage area of the detector can extend the area of the bus stop, a situation that occurred when there were a large number of devices 
detected when the bus stop was near a traffic light. In the area of study, it is uncommon the use of Wi-Fi by the bus transportation users, often constrained due to personal safety reasons. Despite it, Wi-Fi is affordable for this type of project, even though projects-related for people detection mainly approach to close environments. On the other hand, despite the proposed area of interest is outdoors, the delimitation by a relatively small area is characteristic of the bus stops of the case study.

Due to the distance from users to the access point is in a simulated urban environment, their detection is feasible at distances greater than the dimensions of an average bus stop in the city, even under more realistic conditions that address interference, climatic conditions, or concentration of people. As further work, the detection of devices could address mobile networks supported with open source technology, since many users use mobile data as a connection option, including applications deployed with software-defined radio functions for interface simulation.

\section{References}

1. Ahrenholz, J., Goff, T., \& Adamson, B. (2011) Integration of the CORE and EMANE Network Emulators. Baltimore, MD: 2011 - MILCOM 2011 Military Communications Conference, 1870-1875. doi:10.1109/MILCOM.2011.6127585

2. ATM. (2017) Agreement for the construction of smart bus stops in the first road corridors of Guayaquil. Retrieved 02 08, 2021, from

https://www.atm.gob.ec/Show/NewDetails/295?AspxAutoDetectCookieSupport=1

3. ATM. (2018) Moovit, the world's leading transport application comes to Guayaquil to support in the mobility to the citizens. Retrieved 02 08, 2021, from

https://www.atm.gob.ec/Show/NewDetails/517

4. Barth, R. S., \& Galante, R. (2016) Passenger density and flow analysis and city zones and bus stops classification for public bus service management. 31th SBBD - SBBD Proceedings, 2017-2022. Salvador.

5. Cahyana, R. (2018) A preliminary investigation of information system using Ishikawa diagram and sectoral statistics. IOP Conference Series: Materials Science and Engineering, 434. doi:10.1088/1757-899X/434/1/012050

6. El Universo. (2019) Citizens demand solutions to improve public transportation in Guayaquil. Retrieved from eluniverso.com/noticias/2019/02/19/nota/7196120/ciudadania-reclama-solucionesmejorar-transporte-publico

7. El Universo. (2020) Municipality of Guayaquil announces the deployment of 3,000 internet points in educational institutions. Retrieved 02 08, 2021, from

eluniverso.com/guayaquil/2020/07/10/nota/7901535/municipio-guayaquil-anuncia-instalacion-3000puntos-internet

8. Georgievska, S., Rutten, P., Amoraal, J., Ranguelova, E., Bakhshi, R., de Vries, B. L., ... Klous, S. (2019) Detecting high indoor crowd density with Wi-Fi localization: a statistical mechanics approach. Journal of Big Data, 6(31). doi:https://doi.org/10.1186/s40537-019-0194-3

9. INEC. (2017) Ecuador in figures. Retrieved 02 08, 2021, from www.ecuadorencifras.gob.ec/guayaquil-en-cifras/

10. INRIX. (2020) INRIX 2019 Global Traffic Scorecard. Retrieved 02 08, 2021, from https://inrix.com/scorecard/

11. Khodabandelou, G., Gauthier, V., El-Yacoubi, M., \& Fiore, M. (2016) Population estimation from mobile network traffic metadata. 2016 IEEE 17th International Symposium on A World of Wireless, Mobile and Multimedia Networks (WoWMoM), 1-9. Coimbra. doi:10.1109/WoWMoM.2016.7523554

12. Korniyenko, B., Galata, L., \& Ladieva, L. (2019) Research of Information Protection System of Corporate Network Based on GNS3. 2019 IEEE International Conference on Advanced Trends in Information Theory (ATIT), 244-248. Kyiv. doi:10.1109/ATIT49449.2019.9030472

13. Li, D., Zhang, C., \& Cao, J. (2020) Short-Term Passenger Flow Prediction of a Passageway in a Subway Station Using Time Space Correlations Between Multi Sites. IEEE Access, 8, 72471-72484. doi:10.1109/ACCESS.2020.2988030 
14. Li, H., Chan, E. C., Guo, X., Xiao, J., Wu, K., \& Ni, L. M. (2015) Wi-Counter: Smartphone-Based People Counter Using Crowdsourced Wi-Fi Signal Data. IEEE Transactions on Human-Machine Systems, 45(4), 442-452. doi:10.1109/THMS.2015.2401391

15. Lopez, D., \& Lozano, A. (2016) Transport network models for routing algorithms. 2016 IEEE 13th International Conference on Networking, Sensing, and Control (ICNSC), 1-6. Mexico City. doi:10.1109/ICNSC.2016.7479011

16. Makki, A. A., Nguyen, T. T., Ren, J., Al-Jumeily, D., \& Hurst, W. (2020) Estimating Road Traffic Capacity. IEEE Access, 8, 228525-228547. doi:10.1109/ACCESS.2020.3040276

17. Mehmood, U., Moser, I., Jayaraman, P., \& Baner, A. (2019) Occupancy Estimation using WiFi: A Case Study for Counting Passengers on Busses. 2019 IEEE 5th World Forum on Internet of Things (WF-IoT), 165-170. Limerick. doi:10.1109/WF-IoT.2019.8767350

18. Municipality of Guayaquil. (2018) Official Gazette. Retrieved from https://www.guayaquil.gob.ec/Gacetas/Periodo\%202014-2019/Gaceta\%2086.pdf

19. Naranjo, Y. G., \& Arellano, B. (2017) Impact of the Metrovía System in the Center of Guayaquil. Revista Espacios, 38(57), 17.

20. Okereke, M., \& Keates, S. (2018) A Brief Introduction to MATLAB ${ }^{\mathrm{TM}}$. In: Finite Element Applications. Springer Tracts in Mechanical Engineering, 27-45. Springer. doi:https://doi.org/10.1007/978-3-319-67125-3_2

21. Quilambaqui Jara, M., Contreras, D., Sanchez, G., \& Cardenas-Escobar, N. (2019) Experiences and lessons learned with the use of Design Thinking methodologies in university courses in Ecuador. Proceedings of the LACCEI international Multi-conference for Engineering, Education and Technology, 1-11. Jamaica. doi:http://dx.doi.org/10.18687/LACCEI2019.1.1.431

22. Sanchez Padilla, V., Ponguillo, R. A., Abad, A. A., \& Salas, L. E. (2020) Cyber-physical system based on image recognition to improve traffic flow: A case study. International Journal of Electrical and Computer Engineering, 10(5), 5217-5226. doi:10.11591/IJECE.V10I5.PP5217-5226

23. Siuhi, S., Mamun, M. M., \& Mwakalonge, J. (2021) The significance of the posted minimum speed limits along interstate highways in South Carolina on traffic operation and safety. Journal of Traffic and Transportation Engineering (English Edition). doi:https://doi.org/10.1016/j.jtte.2020.10.004

24. Valdivieso, C. E., Valdivieso Castellon, R., \& Valdivieso, O. A. (2011) Sample size determination using decision trees. Revista Investigación \& Desarrollo, 1(11).

25. Vojnak, D. T., Đorđević, B. S., Timčenko, V. V., \& Štrbac, S. M. (2019) Performance Comparison of the type-2 hypervisor VirtualBox and VMWare Workstation. 2019 27th Telecommunications Forum (TELFOR), 1-4. Belgrade. doi:10.1109/TELFOR48224.2019.8971213

26. Wang, Y., Yang, J., Chen, Y., Liu, H., Gruteser, M., \& Martin, R. P. (2014) Tracking human queues using single-point signal monitoring. Proceedings of the 12th annual international conference on Mobile systems, applications, and services (MobiSys '14). doi:https://doi.org/10.1145/2594368.2594382

27. Zhang, J., Yu, X., Tian, C., Zhang, F., Tu, L., \& Xu, C. (2014) Analyzing passenger density for public bus: Inference of crowdedness and evaluation of scheduling choices. 17th International IEEE Conference on Intelligent Transportation Systems (ITSC), 2015-2022. Qingdao. doi:10.1109/ITSC.2014.6958000 